\title{
When Vertical is Horizontal: How Vertical Mergers Lead to Increases in "Effective Concentration"
}

\section{Serge Moresi}

Charles River Associates (CRA), smoresi@crai.com

Steven C. Salop

Georgetown University Law Center, salop@law.georgetown.edu

This paper can be downloaded free of charge from: https://scholarship.law.georgetown.edu/facpub/2341

https://ssrn.com/abstract=3761372

This open-access article is brought to you by the Georgetown Law Library. Posted with permission of the author. Follow this and additional works at: https://scholarship.law.georgetown.edu/facpub

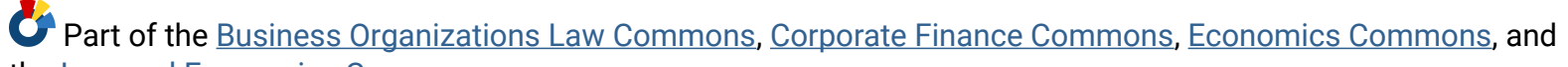
the Law and Economics Commons 


\title{
When Vertical is Horizontal: How Vertical Mergers Lead to Increases in "Effective Concentration"
}

\author{
Serge Moresi and Steven C. Salop*
}

Draft December 26, 2020

\section{Introduction}

It is sometimes claimed that vertical mergers are inherently different from horizontal mergers because there is no elimination of a competitor. ${ }^{1}$ It similarly is said that there is no increase in market concentration, unlike a horizontal merger. ${ }^{2}$ In this article, we explain why both of these claims are false. We show that there in an inherent loss of an indirect competitor that supported the non-merging competitors in the pre-merger world, which leads to reduced competition when there is an input foreclosure concern. We also show that it is possible to calculate an effective increase in the Herfindahl-Hirschman Index (HHI) measure of concentration for the downstream market, when the competitive concern is input foreclosure. We refer to this "proxy" measure as the "dHHI." This increase in effective concentration is separate from any increase in postmerger concentration that might occur in the downstream market if there is foreclose that actually reduces the market shares of foreclosed rivals and increases the market share of the merged firm. The $d H H I$ (and associated post-merger $H H I$ ) can be used as potentially probative evidence in vertical merger matters.

The focus on indirect competition and the possible role for the $d H H I$ proxy can be illustrated by the litigation involving the proposed acquisition of Farelogix by Sabre. ${ }^{3}$ Sabre is a Global Distribution System (GDS) that provides a platform for travel agencies to search and book airline flights. Farelogix provides a technology used by airlines to bypass a GDS and interact directly with the travel agencies. As such, Sabre and the airlines are competing for the travel agencies' booking business, and the acquisition of Farelogix by Sabre was formally a vertical merger.

* The authors are Vice President and Director of Economic Modeling at Charles River Associates (Moresi); Professor of Economics and Law, Georgetown University Law Center, and Senior Consultant at Charles River Associates (Salop). The analysis and opinions expressed here are our own and do not necessarily represent the views of our colleagues or consulting clients. We would like to thank Herb Hovenkamp for helpful comments.

${ }^{1}$ See, e.g., D. Bruce Hoffman, Acting Director, Bureau of Competition, Fed. Trade Comm'n, Vertical Merger Enforcement at the FTC 3 (Jan. 10, 2018),

https://www.ftc.gov/system/files/documents/public_statements/1304213/hoffman_vertical_merger_speec $\underline{\mathrm{h} \text { final.pdf. }}$.

${ }^{2}$ United States v. AT\&T, Inc., 916 F.3d 1029, 1032 (D.C. Cir. 2019).

${ }^{3}$ United States v. Sabre Corp., No. 19-1548-LPS, 2020 U.S. Dist. LEXIS 64637 (D. Del. Apr. 7, 2020). 
However, the Department of Justice (DOJ) characterized the acquisition as a horizontal merger. In doing so, it emphasized statements by Sabre that it competes with Farelogix for providing airlines with access to travel agencies. While accepting this competition, the court rejected the DOJ's complaint because it concluded that Sabre competes on both sides of a two-sided market (i.e., airlines and travel agencies), whereas Farelogix competes only on one side (i.e., airlines). Armed with our analysis, the DOJ alternatively could have framed the proposed acquisition as a vertical merger, but explained to the court that the merger had indirect horizontal effects because Farelogix supported competition between Sabre and the airlines in the market for booking services to travel agencies. The DOJ might have gone further and illustrated the magnitude of the effective reduction in horizontal competition by calculating $d H H I s$ based on Farelogix current sales and also on estimates of its future sales to airlines absent the merger.

The $d H H I$ proxy also might be useful in the formation of safe harbors or anticompetitive presumptions for vertical mergers that raise input foreclosure or downstream output reduction concerns, perhaps in conjunction with other evidence. The Vertical Merger Guidelines do not suggest any safe harbor or anticompetitive presumption based on either shares or concentration. ${ }^{4}$

We previously showed that the first-round incentives to engage in input foreclosure after a vertical merger by raising input prices-which we denote as the upward pricing pressure (UPP)can be related to the analogous UPP resulting from a horizontal merger. In this article, we show how the increase in the effective horizontal concentration (dHHI) from a vertical merger also can be related to these UPP measures. ${ }^{5}$ We specifically derive the $d H H I$ measure by comparing the pricing incentives and associated UPPs involved in two alternative types of acquisitions: (i) vertical mergers that raise unilateral input foreclosure or output reduction concerns (and the associated vertical gross upward pricing pressure index (vertical GUPPI or vGUPPI) measures), and (ii) horizontal acquisitions of partial ownership interests among competitors that raise unilateral effects concerns (and the associated modified GUPPI and modified HHI measures). ${ }^{6}$

\footnotetext{
${ }^{4}$ U.S. DeP'T OF Justice \& Fed. Trade Comm’n, Vertical Merger Guidelines, (June 30, 2020) [hereinafter "VMGs"], https://www.ftc.gov/system/files/documents/reports/us-department-justice-federaltrade-commission-vertical-merger-guidelines/vertical_merger_guidelines 6-30-20.pdf. The draft VMGs released for public comment on January 10, 2020 suggested a safe harbor based on a $20 \%$ market share threshold, under which vertical mergers would have been considered unlikely to be anticompetitive. The agencies received more than 70 comments on the January draft, and the final version included significant improvements, including the elimination of the $20 \%$ market share "safe harbor."
}

${ }^{5}$ Serge Moresi \& Steven. C. Salop, vGUPPI: Scoring Unilateral Pricing Incentives in Vertical Mergers, 79 ANTITRUST L.J. 185 (2013).

${ }^{6}$ U.S. DeP’T OF Justice \& Fed. TRAde COMM’N Horizontal Merger Guidelines 33 (2010) [hereinafter "HMGs"], https://www.ftc.gov/sites/default/files/attachments/mergerreview/100819hmg.pdf; Daniel P. O’Brien \& Steve C. Salop, Competitive Effects of Partial Ownership: Financial Interest and Corporate Control, 67 ANTITRUST L.J. 559 (2000); Andrea Asoni \& Yianis Sarafidis, Economic Tools for Gauging the Competitive Effects of Partial Acquisitions in the Energy Sector, TRANSP., ENERGy \& ANTITRUST, COMM. NEWSLETTER 3 (Summer 2017), 
This connection between the vGUPPIs for vertical mergers and the modified HHIs (mHHIs) for horizontal partial ownership transactions demonstrates the horizontal nature of the concern raised by potential input foreclosure in vertical mergers and how this horizontal concern is connected to the unilateral effects concern from horizontal mergers or horizontal partial ownership transactions. The connection demonstrates that there is not an "inherent" difference in the competitive concerns, as is sometimes claimed. The impact on pricing incentives and effective concentration from input foreclosure concerns is the same as the impact of an identifiable hypothetical horizontal consolidation involving partial ownership interests between the downstream merging firm and its potentially foreclosed rivals.

The $d H H I$ is based on the way in which the pricing incentives that arise in vertical mergers involving unilateral input foreclosure or output reduction concerns are similar to the pricing incentives arising from partial ownership interests among competing firms. It is derived analytically from consideration of two UPP measures - the vGUPPIs used to gauge unilateral input foreclosure effects and the modified GUPPIs ("mGUPPIs") that are used to gauge unilateral price effects from partial ownership interests among horizontal competitors - and the associated $m H H I$ concentration measure. The $d H H I$ analysis also has some intuitive properties that can make it a useful addition to the antitrust toolkit.

We frame our formal analysis of input foreclosure and downstream output reduction incentives in the context of a standard vertical industry model in which the upstream firms are Bertrand competitors selling differentiated inputs to downstream firms, and the downstream firms are Bertrand competitors selling differentiated substitute products to consumers. ${ }^{7}$ The vertically merged firm may have the incentive to engage in an input foreclosure strategy by raising the price of the input charged to one or several targeted downstream rivals. In extreme cases, the merged firm may have the incentive to raise the input price to a prohibitively high level that totally forecloses the (targeted) downstream rivals from access to its input. Such partial or total input foreclosure can be profitable to the merged firm because it can raise the costs faced by the

http://www.crai.com/sites/default/files/publications/Economic-Tools-for-Gauging-the-CompetitiveEffects-of-Partial-Acquisitions-in-the-energy-sector.pdf.

${ }^{7}$ The model assumes for simplicity that there initially are no vertically integrated firms. Each downstream firm sets the price of its product unilaterally, in the sense that it takes the prices charged by all the other firms as given. Similarly, each upstream firm sets the prices of its input to the downstream firms unilaterally (i.e., it takes the prices charged by the other upstream firms as given) but takes into account that raising the price of its input to a given downstream firm will induce that downstream firm to increase its downstream price in response. See Roman Inderst \& Tommaso Valletti, Incentives for Input Foreclosure, 55 EUR. ECON. REV. 820 (2011); Moresi \& Salop, supra note Error! Bookmark not defined.. Other models assume that each upstream firm negotiates bilaterally with each downstream firm over the price of the input. See, e.g., Patrick Rey \& Thibaud Vergé, Secret Contracting in Multilateral Relations (Nov. 26, 2019, https://www.tse-fr.eu/publications/secret-contracting-multilateral-relations; Serge Moresi, Vertical Mergers and Bargaining Models: Simultaneous versus Sequential Pricing (Feb. 19, 2020), https://papers.ssrn.com/sol3/papers.cfm?abstract_id=3541099. 
downstream rivals, and hence can lead to diversion of sales from the downstream rivals to the downstream merging firm. It simultaneously can lead the downstream rivals to raise prices to consumers, which then can allow the downstream merging firm to increase its price, its market share or some combination of the two. ${ }^{8}$

At the outset, we want to emphasize several features of the $d H H I$ and vGUPPI measures as well as some associated caveats and limitations.

First, it is important to recognize that the $d H H I$ measures only the increase in effective concentration in the downstream market. We do not derive a measure of the increase in effective concentration in the upstream market.

Second, our formal model focuses on the effects of a vertical merger on unilateral incentives to raise downstream prices and engage in input foreclosure. It also examines only "first-round" effects. Output reduction and input foreclosure conduct by the merged firm likely also would lead to pricing effects by rival firms at either level of the vertical supply chain. Total foreclosure or price increases by the upstream merging firm may lead its competitors to respond with accommodating input price increases of their own. These price increases might be unilateral (or more strictly, multilateral) or they may be coordinated. ${ }^{9}$ At the downstream level, price increases by the merged firm likely would induce other downstream firms to raise their own prices unilaterally even in the absence of input foreclosure. In addition, input foreclosure may raise the costs of a maverick competitor, which could facilitate downstream coordination. ${ }^{10}$

\footnotetext{
${ }^{8}$ The input foreclosure also could lead to accommodating responses either by the upstream rivals of the merged firm (they also would increase their input prices to the targeted downstream rivals) or by the nontargeted downstream rivals (they also would increase their output prices to consumers). These accommodating responses would exacerbate the anticompetitive effects of input foreclosure. Thomas G. Krattenmaker \& Steven C. Salop, Anticompetitive Exclusion: Raising Rivals' Costs to Achieve Power over Price, 96 YALE L.J. 209 (1986); Janusz A. Ordover, Garth Saloner \& Steven C. Salop, Equilibrium Vertical Foreclosure, 80 AM. ECON. REV. 127 (1990).

${ }^{9} \mathrm{We}$ assume unilateral conduct pre-merger. Intuitively, if pre-merger the upstream merging firm were to raise its input prices to downstream firms, the other upstream firms would not match the price increase because they would anticipate that the upstream merging firm likely would then "cheat" and reduce price. So, upstream coordination does not occur pre-merger. Post-merger, however, upstream coordination targeted at the rivals of the downstream merging firm is more likely to occur than pre-merger. The reason is that the upstream merging firm would have a weaker incentive to "cheat" since reducing its input prices to downstream rivals would reduce the downstream profit earned by the downstream merging firm. See also Hans-Theo Normann, Vertical Integration, Raising Rivals' Costs and Upstream Collusion, 53 EUROPEAN ECON. REV. 461 (2009); Volker Nocke \& Lucy White, Do Vertical Mergers Facilitate Upstream Collusion?, 97 AMERICAN ECON. REV. 1321 (2007).

${ }^{10}$ Downstream coordination increases the profit of the downstream merging firm, but reduces the profit that the upstream merging firm earns from sales to downstream rivals. It is possible that the overall effect of downstream coordination would be to increase the total profits of the merged firm. See also Pedro Mendi, Backward Integration and Collusion in a Duopoly Model with Asymmetric Costs, 96 J. ECON. 95
} 
While coordination can play a role in input foreclosure, we are not explicitly taking account of coordinated effects theories of harm in the formal model. The $d H H I$ (like the vGUPPIs) does not take any of these possibilities into account. However, we will discuss the role of coordinated conduct outside the formal model.

Third, we are focusing on input foreclosure, not customer foreclosure. While the analysis of customer foreclosure is analogous, it also differs in some ways. It typically involves reducing rivals' revenues instead or in addition to increasing rivals' costs. The $d H H I$ (like the vGUPPIs) is not derived here with an eye towards customer foreclosure. ${ }^{11}$

Fourth, because we are focusing on concentration (and its possible use as a safe harbor screen or anticompetitive presumption), the $d H H I$ does not take into account any merger-specific elimination of double marginalization ("EDM") or other cognizable efficiencies. This is the same approach taken for horizontal mergers, where the delta HHI is based on pre-merger market shares and only captures the change in post-merger incentives in a very limited and imperfect way. ${ }^{12}$ Of course, any cognizable EDM or other efficiencies would be analyzed if the merger is investigated further.

The remainder of this paper is organized as follows. In Section II, we show how the vertically merging firms are "indirect competitors" in the pre-merger world and how the merger is a like a horizontal consolidation that eliminates this indirect competition. The indirect competition that we study is not the possibility that an input producer might enter the downstream market in competition with its future downstream merger partner absent the merger. Instead, we mean the input producer supports the downstream competitors of the future downstream merger partner by selling inputs to them. In Section III, we derive the $d H H I$ to proxy for the increase in effective concentration in the downstream market and explain how it can be measured in practice. The $d H H I$ is based on vGUPPIs, the relationship between vertical and horizontal GUPPIs, and the

(2009); Sara Biancini \& David Ettinger, Vertical Integration and Downstream Collusion, 53 INT. J. IND. ORGAN. 99 (2017).

${ }^{11}$ It is the case that customer foreclosure can lead to input foreclosure. For example, suppose customer foreclosure leads a targeted upstream rival or rivals to lose substantial sales and this raises their marginal costs or leads to exit. As a result, the upstream merging firm (and its remaining competitors) may gain the power to raise input prices to the rivals of the downstream firm, either unilaterally or through coordinated action. This input foreclosure then could raise the costs of the downstream rivals and harm consumers. However, our analysis and the $d H H I$ are not directly geared towards this possibility either.

${ }^{12}$ For a summary and citations to the original articles, see Carl Shapiro, The 2010 Horizontal Merger Guidelines: From Hedgehog to Fox in 40 Years, 77 ANTITRUST L. J. 701, 751 (2010). The delta HHI often is considered a screen for the increase in coordination concerns, based on work by Stigler. Willig showed that the delta HHI also is related to the GUPPI under the assumption that diversion ratios are proportional to market shares and market demand is perfectly inelastic. The delta HHI also is related to the increase in the average price-cost margin in the Cournot model, though the use of pre-merger market shares implies that it overstates the increase (since absent efficiencies the market shares of the merging firms will be smaller post-merger than pre-merger). 
$m H H I$ for horizontal acquisitions of partial ownership interests. In Section IV, we discuss how the $d H H I$ can be used in practice to form a general indicator (like the delta HHI in horizontal mergers), a safe harbor, or an anticompetitive presumption. In Section V, we briefly explain that the vGUPPIs themselves could be used instead of the $d H H I$, address some criticisms that have been made of the vGUPPI methodology in two recent papers, and derive simultaneous vGUPPIs in response. Section VI concludes.

\section{The Potential Competitive Effects of Vertical Mergers Are Not Inherently Different from Horizontal Mergers}

While there is no increase in the nominal level of concentration in the downstream market from a vertical merger, our analysis shows that there is a loss of an indirect competitor and therefore an increase in effective concentration in the downstream market. We also show how to derive a proxy $d H H I$ measure for the increase in effective concentration. These two ideas of indirect competition and effective concentration flow from the same economic analysis.

We derive the $d H H I$ measure by comparing the vGUPPIs for vertical mergers (that raise unilateral input foreclosure or downstream output reduction concerns) and the mGUPPIs for horizontal acquisitions of partial ownership interests among competitors (that raise unilateral effects concerns). Specifically, we show that the effects on pricing incentives from a vertical merger are identical to the effects on pricing incentives from a particular hypothetical transaction involving partial ownership interests among the downstream firms (in the sense that the mGUPPIs would be equal to the vGUPPIs). We then define the $d H H I$ as equal to the increase in the $m H H I$ from the equivalent hypothetical horizontal transactions.

These connections between the vGUPPIs and the mHHIs for partial ownership transactions demonstrate the horizontal nature of the concern raised by input foreclosure in vertical mergers and how this horizontal concern can be related to the unilateral effects concern from horizontal mergers or horizontal partial ownership transactions. The connections also demonstrate that the underlying economic analysis does not involve an "inherent" difference in competitive concerns. This latter property is derived in the formal model to follow.

To understand at an intuitive level the relationship between the competitive concerns of the two types of mergers, a useful starting point is the claim that a vertical merger does not inherently eliminate a competitor or competition, unlike a horizontal merger. While this observation might appear to apply in a superficial sense, economic analysis of input foreclosure shows why it is not economically correct. The error is that the claim ignores the fact that in the pre-merger market, the (future) upstream merging firm is an "indirect competitor" of the (future) downstream merging firm. This is because the upstream firm sells inputs to the competitors of the (future) downstream merger partner, and therefore has a role in "supporting" competition in the downstream market by rivals of its (future) downstream merger partner. In this sense, the (future) upstream merging firm has some "indirect control" over the ability of the downstream rivals to compete with the (future) downstream merging firm. By providing inputs to these rivals 
(in competition with other upstream firms), the upstream firm facilitates and increases competition in the downstream market.

However, the vertical merger changes these incentives. After the merger, the upstream merging firm has a unilateral incentive to reduce its support of the downstream competitors and competition. That is because the merger leads the upstream merging firm to take account of the fact that raising input prices to the rivals of the downstream merging firm leads to diversion of downstream sales from the rivals to the downstream merging firm. For this reason, there is an inherent horizontal element to a vertical merger that might lead to anticompetitive effects of input foreclosure.

To illustrate, Example 2 in the 2020 Vertical Merger Guidelines supposes that upstream orange groves supply oranges as inputs in the pre-merger market to juice makers, and it considers a merger between one of the orange groves and one of the juice makers. ${ }^{13}$ Suppose that both the oranges and the juices are differentiated products. Assume further that some juice maker competitors of the downstream merging firm are unable to engage in any substitution by purchasing oranges from other upstream firms, perhaps because only those oranges fit into their juicing machines. ${ }^{14}$ By raising its orange prices to these downstream competitors, the merging orange grove raises the costs of these rivals, which allows it in effect to have some indirect control over the production and pricing incentives of these downstream rivals. ${ }^{15}$ Thus, the vertical merger would allow the merged firm to raise rivals' orange costs in the juice market, thereby possibly creating incentives for each of these targeted rivals to raise their own downstream juice prices.

This raises the question of whether the merged firm would have the incentive to do so. In the pre-merger market equilibrium, the upstream merging firm has no incentive to raise its input orange prices to rivals of the downstream merging juice maker, because the upstream merging firm in the pre-merger world ignores the benefits accruing to the downstream merging firm if its rivals raise their prices. After the merger, however, the merged firm will not ignore and instead will fully internalize the benefits obtained by its downstream division when the targeted rivals raise their juice prices or reduce their juice output (following a targeted input price increase by the upstream firm). It is in this sense that the vertical merger creates a type of indirect horizontal consolidation between the downstream merging juice firm and the foreclosed rival juice firms.

\footnotetext{
${ }^{13}$ VMGs, supra note 4 at 6.

${ }^{14}$ Even here, the incentives to raise input prices to these downstream firms would be limited by a number of factors, including (i) the pass-through of the input price increases into the output prices of these downstream firms, (ii) downstream competition from firms that do not purchase inputs from the upstream merging firm, and (iii) the elasticity of demand in the downstream market.

${ }^{15}$ The upstream merging firm does not exert direct control over the production and pricing decisions of the firms that it supplies (as it would if it owned those firms) but instead it controls them indirectly through changes in the input prices that it charges to them.
} 
The merged firm also will have an incentive to reduce output and increase prices to consumers because it will take account of the fact that an increase in the prices charged to consumers by its downstream division would cause diversion of sales to downstream rivals, who then would purchase more inputs from the upstream merging firm. ${ }^{16}$ This incentive is another inherent horizontal effect, which we refer to as the "Chen effect." 17 Intuitively, from the perspective of the downstream merging firm, the upstream merging firm has a "financial interest" in each downstream rival to which it sells inputs; when the rival sells an additional unit to consumers, the upstream merging firm obtains a "dividend" equal to the upstream merging firm's margin on input sales to that rival. Through the vertical merger, therefore, the downstream merging firm acquires a "financial interest" in each rival supplied by the upstream merging firm. To illustrate, suppose that a rival of the downstream merging firm purchases one unit of input from the upstream merging firm for each unit of output that it produces. Suppose further that the dollar margins of the rival and the upstream merging firm are equal. Then, the vertical merger would have the same effect on the pricing incentives of the downstream merging firm as a hypothetical horizontal merger between the downstream merging firm and the rival. If the dollar margin of the upstream merging firm is smaller than the dollar margin of the downstream rival, the equivalent hypothetical horizontal transaction would be the acquisition of a partial ownership interest in the rival, and not a full merger. This inherent horizontal effect (from the upstream merging firm having a "financial interest" in downstream rivals) is distinct from and in addition to the inherent horizontal effect (from the upstream merging firm having "indirect control" over downstream rivals) discussed in the previous paragraphs.

While the vertical merger has these two inherent horizontal effects, these effects are not equivalent to a horizontal merger. Instead, as we show in our model, they are more closely related to partial ownership transactions among the downstream competitors. It is for this reason that the $d H H I$ proxy measure for vertical mergers is based on the $m H H I$ measure used for horizontal partial ownership transactions.

\section{The $d H H I$ is a Proxy for the Increase in Effective Concentration in the Downstream $\underline{\text { Market }}$}

The $d H H I$ measure is based on two simultaneous, hypothetical partial ownership transactions that would create the same effects on pricing incentives as the vertical merger. In one hypothetical transaction, each of the rivals that would be targeted for input foreclosure obtains a silent (that is, passive, non-voting) partial financial interest in the downstream merging firm. In

\footnotetext{
${ }^{16}$ As indicated previously, we do not take into account any merger-specific EDM or other cognizable efficiencies at this stage of the analysis. As with horizontal mergers, any cognizable efficiencies would be analyzed if the merger is investigated further.

${ }^{17}$ See Yongmin Chen, On Vertical Mergers and Their Competitive Effects, 32 RAND J. ECON. 667, 668 (2001).
} 
the other hypothetical transaction, the downstream merging firm acquires a silent partial financial interest in each of its rivals that purchase the input of the upstream merging firm. The $d H H I$ is equal to the increase in the $m H H I$ from both of these hypothetical horizontal transactions taken together. ${ }^{18}$

\section{A. The Hypothetical Horizontal Transaction to Capture the UPP of the Targeted Downstream Rivals}

The driving force of our analysis is that the merging firms may be indirect competitors in the pre-merger market. If an upstream firm is supplying inputs to the rivals of a downstream firm, that upstream firm is in effect supporting competition in the downstream market by the rivals of that downstream firm. It is in this sense that the upstream merging firm is an indirect competitor of the downstream merging firm in the pre-merger market.

The vertical merger specifically may reduce or eliminate the incentives of the upstream merging firm to support the competition from the rivals of the downstream merging firm. The vertical merger thus creates a type of indirect horizontal consolidation between the downstream merging firm and each foreclosed rival firm. The $d H H I$ concept is a way to capture this consolidation with a concentration measure based on the analysis of the incentive effects of partial ownership interests among competitors. More precisely, instead of thinking about a targeted downstream rival as having an incentive to raise its price because the upstream merging firm raised the input price to that rival, we proxy for this effect by determining that rival's identical incentive to raise price "as if" it had acquired a silent partial financial interest in the downstream merging firm. This equivalent hypothetical horizontal partial ownership transaction is a useful way to look at the potential effect of the vertical merger on the targeted downstream rival. If there are multiple downstream firms targeted for input foreclosure, then there will be additional such hypothetical horizontal transactions. The incentive effect of these hypothetical horizontal transactions can be gauged as an increase in the $m H H I$ of the downstream market. ${ }^{19}$ The $d H H I$ measure then is defined as the increase in the $m H H I$ resulting from these equivalent hypothetical horizontal transactions (and from the other transactions discussed in Section III.B below).

In our vGUPPI article, ${ }^{20}$ we gauge the resulting effect on the pricing incentives of the foreclosed rival(s) with the $v G U P P I r$ measure. ${ }^{21}$ We next briefly review this measure and then explain how

\footnotetext{
${ }^{18}$ For input foreclosure, the VMGs formally define only a downstream market, using the same market definition methodology as in the HMGs. See VMGs, supra note 4 at $§ 3$. In addition, the VMGs define an upstream "related product." Id.

${ }^{19}$ O’Brien \& Salop, supra note 6.

${ }^{20}$ Moresi \& Salop, supra note Error! Bookmark not defined.

${ }^{21}$ The $v G U P P I u$ is related to the $v G U P P I r$ but is not our focus for the derivation of the proxy $d H H I$ of the downstream market.
} 
we derive the hypothetical, equivalent horizontal transaction and the corresponding increase in the $m H H I$.

\section{1. vGUPPIr}

An increase in the input price that the upstream merging firm charges to a downstream rival targeted for input foreclosure would raise the marginal cost of production of the rival, which would give the rival an incentive to raise its own price. This mechanism suggests the relevance of the upward pricing incentives of the downstream rival whose costs would be raised postmerger. The $v G U P P I r$ translates the merged firm's incentive to raise the input price it charges to a foreclosed downstream rival into the resulting impact on the incentive of the foreclosed rival to raise its output price. Formally, ${ }^{22}$

$$
v G U P P I r=P T R_{U} \times D R_{R D} \times M_{D} \times \frac{P_{D}}{P_{R}}
$$

where $P T R_{U}$ denotes the cost pass-through rate of the upstream merging firm, $D R_{R D}$ denotes the diversion ratio from the foreclosed rival to the downstream merging firm, $M_{D}$ denotes the percentage margin earned by the downstream merging firm, and $P_{D} / P_{R}$ denotes the ratio of the prices charged to consumers by the downstream merging firm and the foreclosed rival.

\section{The Equivalent Hypothetical Horizontal Transaction}

As explained above, a key point of our approach is that input foreclosure reduces the intensity of competition that the downstream merging firm faces from the foreclosed rivals. This creates a horizontal effect that is analogous to the reduction in the intensity of competition that would occur if instead of a vertical merger, each targeted rival were to behave "as if" it had acquired a silent partial ownership interest $\left(B_{R D}\right)$ in the downstream merging firm. The effect of such hypothetical, horizontal partial acquisition on a rival's pricing incentives is gauged by the horizontal mGUPPIr. Formally, ${ }^{23}$

$$
m G U P P I r=B_{R D} \times D R_{R D} \times M_{D} \times \frac{P_{D}}{P_{R}}
$$

\footnotetext{
${ }^{22}$ As discussed above, we assume no input substitution. If input substitution is possible, the $v G U P P I r$ is smaller and requires additional information. The assumption of no input substitution is appropriate for our purpose of measuring a potential increase in effective concentration in the downstream market. We discuss this issue in more detail in Section IV.B.

${ }^{23}$ Asoni \& Sarafidis, supra note 6.
} 
where $B_{R D}$ denotes the hypothetical, silent ownership share obtained by the (foreclosed) rival in the downstream merging firm. Note that the factor $D R_{R D} \times M_{D} \times P_{D} / P_{R}$ in equation (2) is the standard horizontal GUPPI of the rival for a hypothetical merger with the downstream merging firm.

Comparing equations (1) and (2), the vertical merger creates UPP on a foreclosed rival that is identical to the UPP that would be created if the rival were to acquire a silent ownership share equal to the cost pass-through rate of the upstream merging firm (i.e., $B_{R D}=P T R_{U}$ ). ${ }^{24}$ Thus, this is the equivalent hypothetical partial ownership transaction.

For example, suppose that the cost pass-through rate is equal to $50 \%{ }^{25}$ Then, for each foreclosed rival, the UPP is identical to that from a hypothetical acquisition by the rival of a $50 \%$ silent ownership share in the downstream merging firm. If there are multiple rivals that would be foreclosed with input price increases, then each of them would behave "as if" it had obtained a $50 \%$ silent ownership share in the downstream merging firm. ${ }^{26}$ The effects of each of these hypothetical transactions involving the targeted downstream rivals would need to be summed up to evaluate the total competitive effect. ${ }^{27}$

\section{Contribution to the $d H H I$ in the Downstream Market}

This UPP analysis thus shows how the impact of potential input foreclosure on the pricing incentives of targeted downstream rivals can be reckoned into a $d H H I$ calculation. The contribution of the $v G U P P I r$ to the $d H H I$ can be measured with the increase in the $m H H I$ from the equivalent hypothetical partial ownership transactions. The $m H H I$ formulation is the following: if Firm-A acquires a silent partial ownership share $\beta$ in Firm-B, the $m H H I$ rises by the magnitude $\beta \times S_{A} \times S_{B}$, where $S_{A}$ and $S_{B}$ are the market shares of the two firms. ${ }^{28}$ The following examples show how this can be applied to input foreclosure.

Example: Consider a downstream market with five firms and assume that each has a $20 \%$ market share. Suppose that the merged firm would be able to target for input foreclosure only one of the four downstream rivals. The

\footnotetext{
${ }^{24} B_{R D}=P T R_{U}$ is obtained by setting (1) equal to (2) and solving for $B_{R D}$.

${ }^{25}$ A cost pass-through rate of $50 \%$ is consistent with linear demand. Carl Shapiro suggested the use of a $50 \%$ pass-through rate as the default rate for horizontal GUPPIs. Shapiro, supra note 12, at 750.

${ }^{26}$ Each foreclosed rival would have a $v G U P P I r$. See Moresi \& Salop, supra note Error! Bookmark not defined., at 200 .

${ }^{27}$ Our analysis uses hypothetical horizontal transactions, not actual horizontal transactions, to proxy for the pricing incentive effects of a vertical merger. For example, the fact that (say) three targeted rivals might behave "as if" each had a 50\% ownership share in the downstream merging firm does not mean that real world ownership shares add up to $150 \%$. Therefore, it does not imply that the increase in effective concentration is overstated.

${ }^{28}$ See O'Brien \& Salop, supra note 6.
} 
contribution to the $d H H I$ in the downstream market can be calculated from the increase in the $m H H I$ from a 50\% silent financial interest transaction. Applying the $m H H I$ formula, the increase in effective concentration in the downstream market, as measured by the $m H H I$, is equal to 200 (i.e., $0.5 \times 20$ x 20).

Example: Suppose instead that the upstream merging firm has two downstream customers that it fully supplies and targets both of them for input foreclosure. In this case, the increase in effective concentration is equal to 400 (i.e., $2 \times 0.5 \times 20 \times 20$ ).

This contribution to the $d H H I$ arises from the impact of input foreclosure on the incentives of the foreclosed downstream rivals. We turn next to the analysis of the impact of the vertical merger on the incentives of the downstream merging firm.

\section{B. The Hypothetical Horizontal Transaction to Capture the UPP of the Downstream Merging Firm}

A vertical merger also changes the incentives of the downstream merging firm, whether or not there are input foreclosure concerns. That is the Chen effect we discussed earlier: the vertical merger reduces the incentive of the downstream merging firm to compete against rivals that are customers of the upstream merging firm. ${ }^{29}$ This is another way in which merging firms may be seen as indirect competitors in the pre-merger market. Suppose that the upstream merging firm is supplying inputs in the pre-merger market to some rivals of the downstream merging firm. For simplicity, assume further that the downstream merging firm is not a customer of the upstream merging firm. ${ }^{30}$ By unilaterally raising its output price, the downstream merging firm will lose some sales, and a fraction of the lost sales will be captured by (i.e., diverted to) rival downstream firms, including those rivals that are customers of the upstream merging firm. It follows that the vertical merger would incentivize the downstream merging firm to raise its output price because doing so would increase the input sales made by the upstream merging firm to the downstream rivals. In the pre-merger market equilibrium, the downstream merging firm has no incentive to raise its output price to gain this effect. This is because the pre-merger downstream merging firm would have no reason to take into account any benefit received by the future upstream merger partner. Post-merger, however, the merged firm will have the incentive to internalize the benefit obtained by its upstream division when the downstream division raises its output price.

\footnotetext{
${ }^{29}$ Chen, supra note 17.

${ }^{30}$ In this simple example, there cannot be any EDM since the downstream merging firm is not a customer of the upstream merging firm. Because we are focusing solely on a measure of effective concentration, we do not take into account any merger-specific EDM or other efficiencies at this stage of the analysis.
} 
The vertical merger creates a type of indirect horizontal consolidation between the downstream merging firm and the rival firms that are customers of the upstream merging firm. As we discussed above, we proxy for this vertical merger effect by considering that the downstream merging firm has an identical incentive to raise price "as if" it had acquired a silent partial financial interest in each of its rivals that are customers of the upstream merging firm. This equivalent hypothetical horizontal transaction is a useful way to gauge the effect of vertical merger on the pricing incentives of the downstream merging firm because it corresponds to an increase in the $m H H I$ of the downstream market.

The driving force of the partial ownership analogy here is that an increase in the price of the downstream merging firm resulting from the vertical merger will cause diversion to other downstream competitors, just as diversion would occur if the downstream merging firm raised its price after acquiring a partial ownership interest in one or more of its competitors.

In our vGUPPI article, we gauged this Chen effect on the pricing incentives of the downstream merging firm with the $v G U P P I d$ measure. We next briefly review this measure and then explain how we derive the hypothetical, equivalent horizontal transaction and the corresponding increase in the $m H H I$.

Before doing so, however, we want to point out that the Chen effect on the downstream merging firm occurs whether or not downstream rivals are foreclosed by the upstream merging firm. ${ }^{31}$ It is a general effect of vertical mergers when rivals of the downstream merging firm are customers of the upstream merging firm. In a full competitive effects analysis, it would mitigate or even reverse the downward pricing pressure ("DPP") from merger-specific EDM.

\section{1. vGUPPId}

The $v G U P P I d$ gauges the post-merger UPP on the output price of the downstream merging firm. It specifically gauges the UPP resulting from the Chen effect - that is, the fact that the merger leads the downstream merging firm to reckon into its incentives the impact of its potential price increase on the profits that the upstream merging firm earns from sales to downstream rivals. Because we are focusing on a $d H H I$ concept corresponding to the approach of the HMGs, the appropriate $v G U P P I d$ measure does not include any potential impact on pricing incentives of merger-specific EDM or other efficiencies. ${ }^{32}$ Note also that this $v G U P P I d$ measure of the

\footnotetext{
${ }^{31}$ Furthermore, this UPP effect - that the downstream division of the merged firm will have an incentive to compete less aggressively in the downstream market if a rival is also a customer of the upstream division - may induce the rival to continue to purchase the input from the upstream division, even if it could obtain the input at a lower price from a different supplier. This is because switching to a different supplier would intensify competition from the merged firm. Chen, supra note 17.

32 The Chen effect corresponds to the $v$ GUPPId 1 measure in our vGUPPI article. The article discusses two other vGUPPId measures that do take account of any merger-specific EDM. Moresi \& Salop, supra note Error! Bookmark not defined.. These would be incorporated into a full competitive effects
} 
merger impact on the incentives of the downstream merging firm is independent of input foreclosure.

The basic equation for the $v G U P P I d$ is written as follows: ${ }^{33}$

$$
v G U P P I d=D R_{D R} \times S_{U R} \times M_{U R} \times \frac{W_{U R}}{P_{D}}
$$

where $D R_{D R}$ denotes the diversion ratio from the downstream merging firm to a given rival, $S_{U R}$ denotes the upstream merging firm's share of that rival's input purchases, $W_{U R}$ and $M_{U R}$ denote the upstream merging firm's price and percentage margin for input sales to that rival, and $P_{D}$ denotes the downstream merger partner's output price. ${ }^{34}$ We consider the diversion to each rival separately and, therefore, the total effect is found by aggregating across all rivals.

As explained above, it is important to recognize that $v G U P P I d$ measures only a first-round effect and fails to take account of a number of important feedback effects. The $v G U P P I d$ specifically holds constant the input prices of the upstream merging firm at the pre-merger level, and thus holds constant both the upstream merging firm's dollar margin (i.e., $M_{U R} \times W_{U R}$ in equation (3)) and the upstream merging firm's share of the rival's input purchases (i.e., $S_{U R}$ in equation (3)). Thus, $v G U P P I d$ scores only the first-round incentive to raise the output price of the downstream merging firm before there are any increases in the input price charged to any foreclosed downstream rivals. Specifically, it does not take account of the impact of raising rivals' costs on the pricing incentives of the downstream merging firm. ${ }^{35}$ Nor does it take account of the impact of raising rivals' costs on the pricing incentives of the competing upstream firms and of the competing downstream firms that are not foreclosed. Nor does it take into account any cognizable EDM. In a full merger analysis, all those effects would be taken into account.

analysis, albeit not a safe harbor analysis before it is known whether the EDM is likely to occur or is merger-specific. See VMGs, supra note 4, §6.

${ }^{33}$ We are using equation (A14) of the technical appendix of our vGUPPI article, with the convention that one unit of output requires one unit of the input under consideration (i.e., $A_{k}=1$ ). That is different from the convention used in equation (3) of our vGUPPI article, where the input share $S_{U R}$ does not appear explicitly in the formula (as it is accounted for in the calculation of the input "price" or input cost per unit of output).

${ }^{34}$ This incentive to raise the price of the downstream merging firm can be explained as follows. If the downstream merging firm raises its price, a fraction of its lost sales $\left(D R_{D R}\right)$ will be diverted to the downstream rival under consideration. However, that rival may use the upstream merging firm for a share $\left(S_{U R}\right)$ of its input purchases, in which case the upstream merging firm gains incremental sales $\left(D R_{D R}\right.$ $\left.\times S_{U R}\right)$ and earns a dollar margin $\left(M_{U R} \times W_{U R}\right)$ on each incremental sale. Normalizing this effect as a percentage of the output price of the downstream merging firm $\left(P_{D}\right)$ yields equation (3).

${ }^{35}$ Similarly, the previous analysis of the pricing incentives of the upstream merging firm did not take account of the impact of raising the output price of the downstream merging firm. 


\section{The Equivalent Hypothetical Horizontal Transaction}

The vertical merger creates UPP on the output price of the downstream merging firm. This creates a horizontal effect that is analogous to the effect that would occur if there were no vertical merger but the downstream merging firm instead were to behave "as if" it had acquired a silent partial ownership interest in each downstream rival that purchases inputs from the upstream merging firm. The effect of such hypothetical, horizontal partial acquisition on the downstream merging firm's pricing incentives is gauged by the horizontal mGUPPId. Formally,

$$
m G U P P I d=B_{D R} \times D R_{D R} \times M_{R} \times \frac{P_{R}}{P_{D}}
$$

where $B_{D R}$ denotes the hypothetical, silent ownership share obtained by the downstream merging firm in the rival under consideration, and $M_{R}$ denotes that rival's percentage margin. Note that the factor $D R_{D R} \times M_{R} \times P_{R} / P_{D}$ in equation (4) is the standard horizontal GUPPI of the downstream merging firm for a hypothetical merger with that rival.

Comparing equations (3) and (4), it follows that the vertical merger creates UPP on the downstream merging firm that is identical to the UPP that would be created if the downstream merging firm instead were to acquire a silent ownership share in that rival equal to: ${ }^{36}$

$$
B_{D R}=\frac{S_{U R} \times M_{U R} \times W_{U R}}{M_{R} \times P_{R}}
$$

In words, this equivalent ownership share is equal to the upstream merging firm's share of the downstream rival's input purchases $\left(S_{U R}\right)$ multiplied by the upstream merging firm's dollar margin on input sales made to that rival $\left(M_{U R} \times W_{U R}\right)$ and divided by the rival's dollar margin $\left(M_{R} \times P_{R}\right)$.

For example, suppose that the ratio of the upstream to downstream dollar margins is 0.3 , and consider a downstream rival that purchases exclusively from the upstream merging firm, that is, $S_{U R}=100 \%$. Then, diversion to that rival creates UPP on the downstream merging firm that is identical to that from a hypothetical acquisition by the downstream merging firm of a $30 \%$ (i.e., $100 \% \times 0.30$ ) silent financial ownership share in that rival. If there are multiple rivals that are customers of the upstream merging firm, then there are additional effects that must similarly be taken into account and added together to obtain the total effect on the $m H H I$.

The effect of the vertical merger on the downstream merging firm's pricing incentives (ignoring EDM) thus is the same as the effect on incentives from a horizontal partial ownership acquisition

\footnotetext{
${ }^{36}$ Equation (5) is obtained by setting (3) equal to (4) and solving for $B_{D R}$.
} 
by the downstream merging firm of each foreclosed downstream rival, where the partial interest is a share $B_{D R}$ that account for the upstream merging firm's share of the downstream rival's input purchases and the fact that the upstream merging firm's dollar margin is typically only a fraction of the downstream rival's dollar margin.

\section{Contribution to the $d H H I$ in the Downstream Market}

This analysis thus shows how the impact of the vertical merger on the incentives of the downstream merging firm to raise price and reduce output, as measured by the $v G U P P I d$, can be reckoned into a $d H H I$ calculation. The contribution of the $v G U P P I d$ to the $d H H I$ can be measured by the increase in the $m H H I$ of the equivalent hypothetical partial ownership transactions. This measure can be used even if there are no input foreclosure concerns. The following examples show how this is calculated.

Example: Consider again the previous example with five symmetric downstream firms that each have $20 \%$ market share. Suppose that the upstream merging firm supplies $100 \%$ of the input needs of a single downstream rival and that this one downstream rival is the only customer of the merged firm. Suppose that the dollar margin ratio (of the upstream merging firm to that rival) is 0.3 . In this example, the increase in effective concentration in the downstream market, as measured by the $m H H I$, is equal to 120 (i.e., $0.3 \times 20 \times 20$ ).

Example: Suppose instead that the upstream merging firm supplies $100 \%$ of the input needs of two downstream rivals and these downstream rivals are the only two customers of the merged firm, and the dollar margin ratio is 0.3 . The increase in effective concentration now is equal to 240 (i.e., $2 \times 0.3 \times 20$ $\mathrm{x} 20) \cdot{ }^{37}$

The increases in the $m H H I$ for these examples reflect only the UPP on the downstream merging firm's output price. The $d H H I$ measure must account for that UPP as well as the UPP on the foreclosed rivals' prices, as discussed next. Before doing so, it is useful to repeat that the incentive of the downstream merging firm to raise price in order to drive additional sales to the upstream merging firm occurs even if there is no foreclosure concern. This can lead to a large $d H H I$ even if there are no foreclosure concerns, which could be relevant to enforcement if merger-specific EDM is small or non-existent. ${ }^{38}$

\footnotetext{
${ }^{37}$ If instead there are two downstream customers but each one purchases only $50 \%$ of its input purchases from the upstream merging firm, then the increase in effective concentration is equal to 120 (that is, $2 \times$ $0.5 \times 0.3 \times 20 \times 20)$.

${ }^{38}$ If there are no foreclosure concerns and the downstream firms are not symmetric, then the UPP may outweigh the EDM of the downstream merging firm when the pre-merger world satisfies some or all of
} 


\section{Calculating the $d H H I$}

The previous sections described two types of hypothetical horizontal transactions that together can be used to proxy for a vertical merger that raises input foreclosure or downstream output reduction concerns, and hence evaluate the merger's impact on effective concentration in the downstream market. These two hypothetical transactions involve several partial ownership interests among the downstream firms, which then can be combined in order to evaluate their total impact on the effective level of concentration in the downstream market. The $d H H I$ measures that total impact.

The $d H H I$ specifically is equal to the sum of the individual dHHIs from each of these proxy transactions, that is, (i) each of the foreclosed rivals acquiring a silent financial interest $B_{R D}=P T R_{U}$ in the downstream merging firm, and (ii) the downstream merging firm acquiring a silent financial interest $B_{D R}=S_{U R} \times M_{U R} \times W_{U R} /\left(M_{R} \times P_{R}\right)$ in each rival that purchases the input of the upstream merging firm. Applying this formula to the two types of hypothetical transactions, we obtain the total increase in the $d H H I$,

$$
d H H I=P T R_{U} \times S_{D} \times S_{F}+\sum_{R} S_{U R} \times \frac{M_{U R} \times W_{U R}}{M_{R} \times P_{R}} \times S_{R} \times S_{D}
$$

where $S_{D}$ denotes the market share of the downstream merging firm, $S_{F}$ denotes the total market share of foreclosed rivals in the downstream market, and $S_{R}$ is the market share of an individual rival of the downstream merging firm. Note that the last term in equation (6) is a summation over all the rivals of the downstream merging firm.

Consider again the case where all the rivals of the downstream merging firm are similarly situated in that they all procure the same share $S_{U R}$ of their input needs from the upstream merging firm, and they all have the same margin ratio $M_{U R} \times W_{U R} /\left(M_{R} \times P_{R}\right)$. If they all are potential targets for input foreclosure, then the above $d H H I$ becomes

$$
d H H I=\left(P T R_{U}+S_{U R} \times \frac{M_{U R} \times W_{U R}}{M_{R} \times P_{R}}\right) \times S_{D} \times\left(1-S_{D}\right)
$$

\footnotetext{
the following properties: (a) the downstream merging firm buys fewer inputs from the upstream merging firm than its rivals do; (b) the upstream merging firm earns a lower dollar margin on input sales to the downstream merging firm than it earns on input sales to rival downstream firms; (c) downstream market demand is sufficiently inelastic; and (d) the downstream merging firm has little ability to substitute inputs from rival suppliers with inputs from the upstream merging firm. However, if there are no foreclosure concerns, then the EDM outweighs the UPP of the downstream merging firm when the downstream firms are symmetric, as shown in Moresi \& Salop, supra note Error! Bookmark not defined., and Chen, supra note 17.
} 
This expression can be used to measure the increase in effective concentration in the downstream market that results from a vertical merger that raises input foreclosure or output reduction concerns.

The $d H H I$ calculation can be illustrated by combining the two parts of the previous numerical examples, where we assume $P T R u=50 \%, M_{U R} \times W_{U R} /\left(M_{R} \times P_{R}\right)=0.3$, and $S_{D}=20 \%$.

Example: Suppose only one downstream rival is customer of the upstream merging firm and purchases the input exclusively from the upstream merging firm (that is, $S_{U R}=100 \%$ ), and this customer is targeted for input foreclosure. Thus, $d H H I=(0.5+0.3) \times 20 \times 20=320$. This is the sum of the $d H H I$ contribution of 200 from the transaction equivalent to the $v G U P P I r$ and a contribution of 120 from the transaction equivalent to the $v G U P P I d$.

Example: Suppose instead that two downstream rivals are fully supplied by the upstream merging firm and are potentially targeted for input foreclosure. In this case, the $d H H I$ is 640 , which is comprised of a contribution of 400 from the transaction equivalent to the $v G U P P I r$ and 240 from the transaction equivalent to the $v G U P P I d$.

These examples indicate the need to identify the set of downstream rivals that might be targeted for input foreclosure by the merged firm. All the rivals must be identified in order to obtain an accurate $d H H I$ measure. If there is no input foreclosure but only downstream output concerns, then the $d H H I$ would include only the second term in equation (6) above.

\section{Applying the $d H H I$ in Vertical Merger Analysis}

The $d H H I$ and the associated post-merger HHI levels have several possible roles in vertical merger analysis. They can be used as a rough gauge of competitive concerns in vertical mergers involving potential input foreclosure or output price increases. They also in principle might be useful in forming a safe harbor screen or a concentration-based anticompetitive presumption for vertical mergers that raise input foreclosure or output reduction concerns, possibly along with other evidence.

\section{A. The Role of the $d H H I$}

The $d H H I$ can be used as an initial, rough screen for the competitive concerns from a vertical merger that involves potential input foreclosure or output price increases. The $d H H I$ only measures first-round effects on pricing incentives, just as do the standard GUPPIs used in horizontal merger analysis. Focusing on these first-round effects, a higher $d H H I$ suggests greater anticompetitive concerns.

These first-round effects on pricing incentives specifically exclude the following feedback effects. 
First, the first-round effects do not take into account the impact of the pricing incentives of the targeted rivals (following input foreclosure) on the pricing incentives of the downstream merging firm. Nor do they take into account the impact of the pricing incentives of the downstream merging firm on the pricing incentives of the targeted rivals. These feedback effects could exacerbate the competitive harms, just as is the case for horizontal mergers. In Section V, we show how simultaneous effects on pricing incentives can be calculated, just as they can for horizontal GUPPIs. ${ }^{39}$

Second, the first-round effects assume that non-targeted downstream firms do not change their prices in response to the foreclosure of the targeted downstream rivals. Since the foreclosed rivals will have the incentive to raise their prices, these non-targeted competitors would tend to have the incentive to respond by raising their prices. This also creates feedback effects among the price increases that could exacerbate the competitive harms further, just as it occurs for horizontal mergers.

Third, the first-round effects do not take into account possible entry or repositioning by competing upstream firms or non-targeted downstream firms. Nor do they take into account possible repositioning by the upstream and downstream divisions of the merged firm. These effects could mitigate or offset the competitive harms, just as is the case for horizontal mergers.

Fourth, the first-round effects taken into account in the $d H H I$ do not include any downward pricing pressure from cognizable efficiency benefits, including EDM. These effects would mitigate or offset the competitive harms, if they are cognizable, just as it occurs for horizontal mergers. These effects would be included in a full competitive effects analysis, but not in a proxy concentration measure used for a safe harbor screen or an anticompetitive presumption. This is the approach in the HMGs, even though it commonly is said that many horizontal mergers also generate efficiency benefits.

Fifth, the first-round effects in equation (1) do not account for the possibility of any input substitution by the targeted downstream rivals, whereby the targeted rivals would reduce input purchases from the merged firm and increase input purchases from upstream rivals of the merged firm. Nor do they account for accommodating responses by those upstream competitors, whereby the upstream competitors also would increase the input prices charged to the targeted downstream firms. However, as we discuss below, equation (1) would remain a good approximation if input substitution were possible and the competitors of the upstream merging firm would respond to the increase in demand for their inputs by matching the upstream merging firm's price increases. The input substitution tends to reduce the upstream merging firm's

\footnotetext{
${ }^{39}$ The simultaneous GUPPIs for horizontal mergers are equal to the compensating marginal cost reductions ("CMCRs") expressed as a percentage of price. Gregory J. Werden, A Robust Test for Consumer Welfare Enhancing Mergers Among Sellers of Differentiated Products, 44 J. INDUS. ECON. 409 (1996). The corresponding price increases also can be calculated if one assumes linear demand. Jerry Hausman, Serge Moresi \& Mark Rainey, Unilateral Effects of Mergers with General Linear Demand, 111 ECON. LETTERS 119 (2011).
} 
incentive to raise its input prices to targeted downstream rivals, which tends to reduce the increase in the marginal cost of the targeted rivals, and hence reduces the targeted rivals' incentives to raise their output price. At the same time, the accommodating input price increases by upstream competitors tend to increase the targeted rivals' marginal costs, which in turn tends to increase their incentives to raise output prices to consumers. The combined assumptions of no input substitution and no accommodating price responses by upstream rivals is the simplest case to analyze for the $d H H I$.

\section{B. Input Substitution}

Our derivation of the $\mathrm{dHHI}$ assumes that the downstream rivals targeted for input price increases by the upstream merging firm are unable to substitute the input of the upstream merging firm with inputs supplied by other upstream firms. We have made this assumption for several reasons.

First, it substantially simplifies the data requirements and calculations. For the $d H H I$, the analyst needs the following data: the upstream cost pass-through rate $\left(P T R_{U}\right)$, the market share of the downstream merging firm $\left(S_{D}\right)$, the total market share of the foreclosed downstream rivals $\left(S_{F}\right)$ and, for each downstream rival, the rival's market share $\left(S_{R}\right)$, the upstream merging firm's share of the rival's input purchases $\left(S_{U R}\right)$, the input price paid to the upstream merging firm by the rival $\left(W_{U R}\right)$, the percentage margin earned by the upstream merging firm on input sales to the rival $\left(M_{U R}\right)$, and the percentage margin $\left(M_{R}\right)$ and output price $\left(P_{R}\right)$ of the rival. These data often are readily available.

Our vGUPPI article explains how the vGUPPIs are altered when there is input substitution and describes the additional data requirements. ${ }^{40}$ The $d H H I$ also would require data on the downstream pass-through elasticity $\left(E_{P}\right)$, which might not be so difficult to estimate. ${ }^{41}$ However, the $d H H I$ calculation also would require an estimate of the "elasticity of substitution" $\left(E_{S R}\right)$, which can be difficult to estimate precisely. ${ }^{42}$ The estimation of this elasticity might require a full study of the input market. ${ }^{43}$

${ }^{40}$ Moresi \& Salop, supra note Error! Bookmark not defined., at 202-204.

${ }^{41} E_{P}$ denotes the elasticity of the price of the targeted rival $\left(P_{R}\right)$ with respect to an increase in the input price that the rival must pay to the upstream merging firm $\left(W_{U R}\right)$.

${ }^{42} E_{S R}$ denotes the elasticity of the upstream merging firm's share of the rival's input purchases $\left(S_{U R}\right)$ with respect to an increase in the input price that the rival must pay to the upstream merging firm $\left(W_{U R}\right)$.

${ }^{43}$ Our vGUPPI article provides a method for "calibrating" the values of $E_{P}$ and $E_{S R}$, but this requires assuming pre-merger symmetric downstream firms and obtaining estimates for the downstream cost passthrough rate $\left(P T R_{R}\right)$ and the aggregate price elasticity of downstream market demand $(E)$. Moresi \& Salop, supra note Error! Bookmark not defined., at 205. In addition, the calibration of $E_{P}$ can be more complicated when there are multiple targeted rivals. Id. at n. 49 . 
In fact, the study of upstream competition would need to go even further. When there is no input substitution, the focus on first-round effects and the assumption that upstream competitors' prices are constant do not create any distortion. When there is input substitution, the $v G U P P I r$, $m G U P P I r$ and $d H H I$ would be lower, if it is assumed that the upstream competitors' prices do not change. However, a more reliable analysis should recognize that input substitution increases the demand faced by upstream rivals, and thus upstream rivals may have an incentive to raise their prices in response to the price increase by the upstream merging firm. Taking these likely reactions into account would require a more complex analysis of upstream competition. The role of the $d H H I$ calculation is to provide a rough indicator, not to capture all the complexities of competition. If the agencies decide to investigate the merger further, those complexities could be analyzed using simulation models, econometrics, analysis of business strategy documents, and so on. The accommodating response by upstream competitors may be predicted to be larger if the upstream market is more concentrated, if the inputs are less differentiated or if the suppliers have rising marginal costs.

Second, if the $d H H I$ were used as part of a safe harbor for vertical mergers involving input foreclosure concerns, a conservative approach to the $d H H I$ should be taken. If the upstream competitors were to match the input price increases of the upstream merging firm, that likely would completely offset the effects of input substitution, and hence input substitution would not occur. If instead the upstream rivals would not fully match, then there would be some input substitution and that would tend to reduce the $d H H I$ depending on the elasticity of substitution and the extent of partial price matching. The $d H H I$ that we have proposed (assuming no input substitution and no responses by upstream rivals) likely is a good approximation for the case with both input substitution and responses from upstream rivals. While one cannot claim that there would be full price matching by upstream rivals and hence no input substitution, that assumption is the conservative one. ${ }^{44}$ The assumption of full matching also might suggest a conservative approach to any anticompetitive presumption based solely on the $d H H I$ (and associated post-merger $H H I$ ).

\section{The vGUPPI Methodology, Feedback Effects, and Simultaneous vGUPPIs}

Preliminary analysis of vertical mergers involving input foreclosure or output reduction concerns might focus directly on the vGUPPIs themselves rather than using the partial ownership $d H H I$ proxy that is based on the vGUPPIs. If there is no input substitution, these vGUPPIs are relatively simple to calculate, as shown above in equations (1) and (3).

As already discussed, the vGUPPIs measure only first-round effects. They do not take into account the pricing responses of upstream rivals and non-foreclosed downstream rivals of the merged firm. The individual vGUPPIs also hold the merging firms' other prices at the premerger level. In particular, $v G U P P I r$ measures the UPP for the price of the output sold by a

\footnotetext{
${ }^{44}$ In addition, all the potentially foreclosed firms should be included in the analysis.
} 
foreclosed rival, while holding constant the price of the output sold by the downstream merging firm. Similarly, $v$ GUPPId measures the UPP for the price of the output sold by the downstream merging firm, holding constant the price of the input that the upstream merging firm charges to rival downstream firms. This is the same approach used in calculating the GUPPIs for horizontal mergers that are discussed in the HMGs. As a first-round analysis, the vGUPPId utilized for the $d H H I$ also does not take cognizable EDM or other efficiencies into account. This is also the approach used in calculating the horizontal merger GUPPIs.

Two recent papers have suggested that these assumptions render the vGUPPI methodology as inherently flawed. In particular, the $v G U P P I u$ always predicts that the merged firm will have an incentive to raise rivals' costs, but a simulation model that takes into account the existence of significant merger-specific EDM may predict that the merged firm actually will decrease the input price that it charges to downstream rivals. ${ }^{45}$ These papers also have suggested that $v G U P P I r$ is similarly a poor proxy for the downstream effects in the presence of merger-specific $\mathrm{EDM}$, because $v G U P P I r$ always predicts that the foreclosed rivals will have an incentive to raise price, whereas there can be situations where a simulation model predicts that rivals' costs will be raised and yet all consumer prices will fall.

\section{A. Explaining the Feedback Effects}

In our view, these criticisms miss the mark. The criticisms mistake an initial screen for a full merger analysis. For example, while these papers focus on vertical mergers, similar criticisms can be made about the use of standard GUPPIs in horizontal mergers when there are cognizable efficiency benefits. ${ }^{46}$ The criticisms further assume that EDM will always occur, will be relatively large, and will be merger-specific. However, EDM may not satisfy these conditions for many mergers.

\footnotetext{
${ }^{45}$ Gopal Das Varma \& Martino De Stefano, Equilibrium Analysis of Vertical Mergers, 65 ANTITRUST BULLETIN 455 (2020), https://doi.org/10.1177/0003603X20929138 ("Under certain commonly used assumptions, a vertical merger may even create an incentive for the merged firm to lower its rivals' cost."); Gleb Domnenko \& David S. Sibley, Simulating Vertical Mergers and the Vertical GUPPI Approach (Jan. 1, 2019), https://papers.ssrn.com/sol3/papers.cfm?abstract_id=3447687 ("In the simulations, the upstream price paid by the remaining downstream rival can either rise or fall.").

${ }^{46}$ The GUPPIs for horizontal mergers are always positive in the absence of efficiencies. Consider a horizontal merger of Firm-A and Firm-B, and suppose the merger will generate cost savings for Firm-A only. Suppose the net UPP for the product of Firm-A is negative, so that on balance there is downward pricing pressure on the price charged by Firm-A. That does not affect the GUPPI of Firm-B which remains positive. However, a merger simulation model might predict that the prices of both Firm-A and Firm-B will fall. For example, this can occur if demand is linear, the diversion ratio from Firm-A to Firm-B is relatively high, and the diversion ratio from Firm-B to Firm-A is relatively low.
} 
The criticisms also are misplaced because our 2013 article did not ignore EDM but rather cautioned about potential price feedback effects within the merging firms. ${ }^{47}$ In fact, that article reported several $v$ GUPPId measures: $v$ GUPPId 1 does not take EDM into account because EDM may not occur or may not be merger-specific; $v G U P P I d 2$ takes merger-specific EDM into account and may be negative; and $v$ GUPPId 3 takes EDM into account and assumes further efficiencies from input substitution. ${ }^{48}$

The $v G U P P I d 1$ measure is always positive, reflecting the fact that the downstream division of the merged firm has an incentive to raise price to consumers because it takes into account that raising its price and losing sales to rival downstream firms will lead those rivals to purchase additional inputs from the upstream division. Where there is no cognizable EDM, $v$ GUPPIdI and $v G U P P I r$ (or $v G U P P I u$ ) will understate the ultimate incentives to raise price because they ignore feedback effects that would reinforce one another. ${ }^{49}$

When there is merger-specific EDM, the situation is different. Merger-specific EDM can mitigate the UPP from $v$ GUPPId 1 or even reverse the effect and create DPP. That is, $v$ GUPPId 2 can be negative if merger-specific EDM is relatively large. In this situation, the $v G U P P I r$ (or $v G U P P I u$ ) will overstate the ultimate incentive to raise price because it ignores feedback effects. To account for these feedback effects, we suggested that a full-blown vertical merger simulation model might be estimated and run. ${ }^{50}$ The two papers discussed here took this suggested simulation approach and compared their results with the simple vGUPPIs for the case where there is an upstream monopolist that is the only potential supplier to all the downstream firms. With a monopolist input supplier and linear input prices, the pre-merger upstream margin of the monopolist is relatively high and, therefore, a vertical merger is bound to generate relatively large EDM.

In these conditions, the $v G U P P I u$ and $v G U P P I r$ measures may not perform well in comparison to simulation models in the sense that they may have the wrong sign. This will depend on the structure of the demand and competition. In the case with linear demand and two perfectly symmetric downstream firms, for example, equilibrium upstream and downstream prices fall after a vertical merger between the upstream monopolist and one of the two downstream firms. ${ }^{51}$ If the competitors in the downstream market are not symmetric, prices may either rise or fall,

\footnotetext{
${ }^{47}$ Moresi \& Salop supra note Error! Bookmark not defined. at 187, 190.

${ }^{48}$ Moresi \& Salop supra note Error! Bookmark not defined. at 197-99.

${ }^{49}$ They also would be reinforced by the accommodating price responses of non-merging firms.

${ }^{50}$ Moresi \& Salop supra note Error! Bookmark not defined. at n.39.

${ }^{51}$ See Shihua Lu, Serge Moresi \& Steven C. Salop, A Note on Vertical Mergers with an Upstream Monopolist: Foreclosure and Consumer Welfare Effects, (June 2007), at 15, https://www.crai.com/sites/default/files/publications/Merging-with-an-upstream-monopolist.pdf. This earlier unpublished article used a linear demand model and was a building block for the two papers.
} 
depending on the type of asymmetry and the downstream market elasticity. If downstream firms can engage in coordinated conduct, rather than the unilateral conduct assumed in the vGUPPIs and standard simulation models, prices may not fall because the merger may facilitate downstream coordination. ${ }^{52}$

The simulation results presented in those two papers are straightforward to explain. First, those studies consider situations where EDM is relatively large. When merger-specific EDM is relatively small, $v G U P P I u$ and $v G U P P I r$ perform well. In fact, as noted above, $v G U P P I d 2$ is positive when EDM is relatively small, and a positive $v G U P P I d 2$ reinforces the UPP from the $v G U P P I r$ or $v G U P P I u$.

Second, the vGUPPIs gauge only first-round effects and do not take into account pricing feedback effects between the two merging firms. The feedback effects can be important and should be taken into account when merger-specific EDM is relatively large. It also is clear that the net effect can be to reduce all prices paid by downstream rivals and consumers, if mergerspecific EDM is large enough.

Third, our 2013 article stated that 53 "If $v G U P P I d<0$, it will mitigate and possibly reverse the impact of $v G U P P I r>0$, which would lead to a lower likelihood of significant adverse effects. The first-round net incentive effect on downstream prices then might be gauged roughly by calculating a weighted average of $v G U P P I r$ and $v G U P P I d . "$ In fact, it is straightforward to account for feedback effects between the pricing incentives of the two merging firms. This involves simultaneously adjusting the $v G U P P I u$ of the upstream merging firm and the $v G U P P I d 2$ of the downstream merging firm to account for the feedback effects. We call these adjusted vGUPPIs the "simultaneous vGUPPIu" and "simultaneous vGUPPId2," and denote them by "SvGUPPIu" and "SvGUPPId2" respectively. They are derived in the same way as the simultaneous GUPPIs for horizontal mergers. ${ }^{54}$ The simultaneous vGUPPIs can be used to account for the feedback effect of merger-specific EDM ( $v G U P P I d 2)$ on input foreclosure incentives $(v G U P P I u)$.

\section{B. Simultaneous vGUPPIs}

We turn next to the derivation of these simultaneous vGUPPIs. Consider the model used in the two papers: a monopolist upstream supplier (U) sells inputs to two downstream manufacturers (D and R) and wants to merge with D. The SvGUPPIu and SvGUPPId2 are expressed as a percentage of price and are given by the following system of two equations:

\footnotetext{
${ }^{52}$ See Mendi and Biancini \& Ettinger, supra note 10.

${ }^{53}$ Moresi \& Salop supra note Error! Bookmark not defined., at 199.

${ }^{54}$ See supra note 39.
} 


$$
\begin{gathered}
\text { SvGUPPIu }=D R_{R D} \times\left(M_{D}+\text { SvGUPPId } 2\right) \times \frac{P_{D}}{W_{U R}} \\
\text { SvGUPPId } 2=-M_{U D} \times \frac{W_{U D}}{P_{D}}+D R_{D R} \times\left(M_{U R}+\text { SvGUPPIu }\right) \times \frac{W_{U R}}{P_{D}}
\end{gathered}
$$

where $M_{U D}$ and $W_{U D}$ denote the percentage margin and input price of the upstream merging firm $\mathrm{U}$ for input sales to the downstream merging firm $\mathrm{D}$ in the pre-merger market. Note that, if we set $S v G U P P I d 2=0$ in equation (8), then equation (8) reduces to the simple $v G U P P I u$ of our article. Similarly, if we set $S v G U P P I u=0$ in equation (9), then equation (9) reduces to the simple $v$ GUPPId 2 of our article. The presence of the two vGUPPIs in both equations (8) and (9) captures the feedback effects.

Solving equations (8) and (9) simultaneously for SvGUPPI $u$ and $S v G U P P I d 2$ yields the following simultaneous vGUPPIs, which have the form of a weighted sum of the simple $v G U P P I u$ and $v$ GUPPId 2 :

$$
\begin{aligned}
& \text { SvGUPPIu }=Z \times\left(v G U P P I u+D R_{R D} \times v G U P P I d 2 \times \frac{P_{D}}{W_{U R}}\right) \\
& \text { SvGUPPId2 }=Z \times\left(v G U P P I d 2+D R_{D R} \times v G U P P I u \times \frac{W_{U R}}{P_{D}}\right)
\end{aligned}
$$

where $Z=1 /\left(1-D R_{R D} \times D R_{D R}\right)$ is a scale factor that exceeds unity. Equations (10) and (11) show how to obtain the simultaneous vGUPPIs that account for feedback effects between the merging firm's incentives using the simple vGUPPIs provided in our vGUPPI article (which do not account for feedback effects).

To see the impact of the feedback effects, note that in equation (10) the simultaneity leads to $S v G U P P I u>v G U P P I u$ when $v G U P P I d 2 \geq 0$. This is because $v$ GUPPId 2 is first-round and thus implicitly assumes $v G U P P I u=0$. But since $v G U P P I u>0$, we see from equation (11) that $S v G U P P I d 2>0$ (when $v$ GUPPId $2 \geq 0$ ) and hence it follows from equation (8) that SvGUPPIu $>v G U P P I u$ (when $v G U P P I d 2 \geq 0$ ). Intuitively, even if there were no first-round effect on the pricing incentives of the downstream merging firm, there will be a second-round effect because 
of the first-round effect on the pricing incentives of the upstream merging firm, which will then lead to a second-round effect on the pricing incentives of the upstream merging firm, and so on. ${ }^{55}$

The two papers focus on the situations in which the simple $v G U P P I d 2$ is negative and relatively large, so that it is possible that the simultaneous $v G U P P I u$ in equation (10) turns negative. ${ }^{56}$ If EDM is large and merger-specific, then a full competitive effects analysis must account for the interaction of the upward and downward pricing pressure. The above simultaneous vGUPPIs attempt to account for that interaction. This is why the simple first-round vGUPPIs are not intended to serve as a complete competitive effects analysis. ${ }^{57}$

While $v G U P P I u$ can turn negative when EDM is merger-specific and relatively large, we caution that the presence of large merger-specific EDM is not inevitable and cannot be assumed on faith. ${ }^{58}$ Indeed, a recent article reported empirical evidence from a large database of vertically integrated firms that indicated that there were no internal input transfers from the upstream division to the downstream division in about half of all the vertically-integrated firms studied. ${ }^{59}$ And there are numerous reasons why EDM would not occur even when there are internal transfers of inputs. ${ }^{60}$

Finally, the two papers assume that the upstream merging firm is a monopolist. In a nonmonopoly scenario, the upstream merging firm would face competition and that affects the analysis. Upstream competition reduces the pre-merger equilibrium upstream margin below the monopoly level, and a lower upstream margin implies that a vertical merger leads to smaller EDM ${ }^{61}$ In addition, in a non-monopoly scenario with input substitution, the upstream

\footnotetext{
${ }^{55}$ Similarly, when $v G U P P I u \geq 0$ in equation (11), the simultaneity leads to $|\operatorname{SvGUPPId} 2|>|v G U P P I d 2|$. This is because $v G U P P I u$ is first-round and thus implicitly assumes $v G U P P I d 2=0$. But if $v G U P P I d 2<$ 0 , we see from equation (10) that $S v G U P P I u<0$ (when $v G U P P I u \geq 0$ ) and hence it follows from equation (9) that $|S v G U P P I d 2|>|v G U P P I d 2|$ (when $v G U P P I u \geq 0$ ).

${ }^{56}$ The two studies compare simulation results with the simple vGUPPIs, not with the simultaneous vGUPPIs. We are not suggesting that the simultaneous vGUPPIs always would have been much closer to the simulation results than the simple vGUPPIs. But they are an easy step in the right direction.

${ }^{57}$ Moresi \& Salop, supra note Error! Bookmark not defined. at 190.

${ }^{58}$ For example, with secret contracting and non-linear input prices, there is no EDM because pre-merger suppliers set marginal prices equal to marginal costs. Rey \& Vergé, supra note 7, at 68-69.

${ }^{59}$ See Enghin Atalay, Ali Hortaçsu \& Chad Syverson, Vertical Integration and Input Flows, 104 AM. ECON. REV. 1120, 1127 (2014).

${ }^{60}$ See Jonathan B. Baker, Nancy L. Rose, Steven C. Salop \& Fiona Scott Morton, Recommendations and Comments on the Draft Vertical Merger Guidelines (February 24, 2020), https://papers.ssrn.com/sol3/papers.cfm?abstract_id=3543736; John Kwoka \& Margaret Slade, Second Thoughts on Double Marginalization, 34 ANTITRUST 51 (2020).

${ }^{61}$ As a result of upstream competition, the upstream merging firm earns a smaller margin and sells fewer inputs to rivals of the downstream merging firm, which implies that the upstream loss from foreclosure is smaller and hence the incentive to foreclose is stronger than it would be absent upstream competition. See Serge Moresi \& Marius
} 
competitors have the incentive to accommodate post-merger changes in the input price charged by the merged firm. Thus, the overall results in a full-blown vertical merger simulation model that takes into account upstream competition could differ substantially from their estimates in the monopoly model. A model of a monopoly supplier is not the best model to guide vertical merger policy. Few mergers involve monopolists and the monopoly model can be a poor predictor of merger effects in oligopoly markets. Thus, it is false to claim that these papers show that vGUPPI analysis is inherently flawed, that RRC and EDM are necessarily highly correlated or that the Agencies should have the burden of proof to show that merger-specific EDM will not occur, rather than the conventional antitrust approach of allocating the burden to show mergerspecific efficiencies on the merging parties. ${ }^{62}$

\section{Conclusions}

The $d H H I$ shows that vertical mergers involving input foreclosure or output reduction concerns have an analogue to horizontal consolidation in the downstream market. This is a significant result because it shows that there is not the type of inherent difference in the effects of vertical and horizonal mergers that is sometimes claimed. At the same time, we do not want to overclaim that the use the $d H H I$ and the resulting post-merger $H H I$ is an airtight gauge of the likely impact of vertical mergers that raise input foreclosure or output reduction concerns. As we have stressed in this paper, the $d H H I$ gauges only first-round effects and only for unilateral input foreclosure and unilateral output price increases. The same point applies to analysis directly based on the levels of the vGUPPIs. However, we are confident that using the HHI either alone or in conjunction with our $d H H I$ approach would provide a useful gauge. Therefore, we believe that the $d H H I$ approach should be investigated further.

Schwartz, Vertical Mergers with Input Substitution: Double Marginalization, Foreclosure and Welfare (December 10, 2020), https://papers.ssrn.com/sol3/papers.cfm?abstract_id=3743708.

${ }^{62}$ See Koren Wong-Ervin, U.S. Vertical Merger Guidelines: Recommendations and Thoughts on EDM and Merger Specificity (January 21, 2020), https://papers.ssrn.com/sol3/papers.cfm?abstract_id=3523652. 